\title{
Patterns in residential urban forest structure along a synthetic urbanization gradient
}

\author{
Adam Berland $^{1}$ and Steven M. Manson ${ }^{2}$ \\ ${ }^{1}$ Institute for the Environment and Sustainability, Miami University, 254 Upham Hall, Oxford, \\ $\mathrm{OH} 45056$ \\ ${ }^{2}$ Department of Geography, Environment and Society, University of Minnesota, 414 Social \\ Sciences, $26719^{\text {th }}$ Ave S, Minneapolis, MN 55455
}

\begin{abstract}
The environmental sciences increasingly need to understand the ecological effects of urbanization. This is especially true for the urban forest, a major component of the urban environment that is relied upon to provide ecosystem services such as air pollution removal and stormwater interception. The urbanization gradient is a popular organizing concept for assessing ecological response to varying urbanization intensity, and recent methodological improvements have moved beyond simple distance-based gradients to more sophisticated synthetic gradients based on urbanization indicators such as population density and impervious surface intensity. While these synthetic gradients provide a more complete picture of urbanization than any one indicator alone can provide, it is unclear how synthetic gradients relate to ecological structure. In this study, we collected field data on urban forest structure from 150 residential properties over a $40 \mathrm{~km}$ transect in Minnesota's Twin Cities Metropolitan Area. We then applied factor analysis to a set of nineteen urbanization indicators, and extracted two primary urbanization trends strongly related to distance from the urban core and residential neighborhood density, respectively. We related the synthetic gradient to urban forest structure using polynomial regression models. The synthetic gradient explained nine of the fourteen urban forest structural variables assessed, and improved upon a simple distance-based gradient by explaining patterns in tree canopy cover. Our findings demonstrate the need to consider the effects of secondary urbanization trends on ecological structure. These results support the continued application of synthetic gradient approaches to understanding the relationships between urbanization and ecological structure.
\end{abstract}

Key Words: residential land, urban forest structure, urbanization gradient

Citation: Berland A, Manson SM. 2013. Patterns in residential urban forest structure along a synthetic urbanization gradient. Annals of the Association of American Geographers 103(4): 749-763.

\section{AUTHOR'S PREPRESS VERSION}




\section{INTRODUCTION}

Urbanization is a widespread and fundamental land change process with increasingly apparent relevance to the environmental sciences (Wang et al. 2012). In the United States, urban land area is expected to increase by 79 percent between 1997 and 2025 (Alig, Kline, and Lichtenstein 2004). Rapid urban expansion has important consequences for the structure of ecological systems within metropolitan regions, with impacts including diminished air and water quality, habitat destruction, and altered microclimatic patterns. These impacts in particular, and the linkages between urbanization and the environment more generally, need to be understood in order to maintain and enhance biodiversity, sustainability, and ecosystem services within urban areas (Alberti and Susskind 1996; McPherson 1998; Williams et al. 2009).

Two decades ago, ecologists began to argue that gradient analysis, a classic ecological approach, was well suited to investigating urban areas because human impacts are generally greatest in the urban core and decrease with distance from the core (McDonnell and Pickett 1990). As urban ecology grew into its own distinct discipline, the urban-rural gradient approach became a key organizing principle in studying the effects of urbanization on ecological systems (e.g., Medley, McDonnell, and Pickett 1995; McDonnell et al. 1997; Porter, Forschner, and Blair 2001). However, while gradients offer a useful organizing concept, simple linear transects from

the urban core to the rural periphery inadequately capture crucial dynamics such as time lags and nonlinearities that are typical in complex human-environmental systems (Liu et al. 2007; McDonnell and Hahs 2008). Consequently, recent research has focused on what we term “character-based" synthetic gradients to describe urbanization intensity (Hahs and McDonnell 2006; du Toit and Cilliers 2011). Character-based gradients combine multiple urbanization indicators (e.g., population density, proportion of impervious surfaces, land cover diversity), in 
addition to linear distance from the urban core that defines simpler "distance-based" gradients.

One key application of character-based gradients is examining how urbanization affects ecological systems, yet this research area remains under-explored (McDonnell and Hahs 2008). The urban forest—defined here as all trees and woody shrubs within an urban area—is an appropriate subject for studying urbanization-ecological relationships, because it is a critical component of most urban ecological systems (Dwyer et al. 1992; McPherson et al. 1997; Nowak et al. 2001). For example, urban trees provide a suite of environmental benefits including stormwater interception, urban microclimate regulation, air pollution removal, and improved animal habitat (Nowak and Dwyer 2007). As we continue to learn more about the urban forest's effects on ecosystems, it is increasingly important to understand how urbanization intensity relates to urban forest structure as defined by the number, size, and spatial configuration of trees and woody shrubs. Identifying how urban forest structure relates to primary trends along urbanization gradients would substantially improve conceptualizations of how urbanization impacts the urban forest.

Private lands are an important focus of study because only a small percentage of the urban forest is publicly maintained (McPherson 1998), and residential areas in particular are critical because they can comprise about half of urban land area and over half of new urban growth (Akbari, Rose, and Taha 2003; Yuan et al. 2005). Moreover, the residential urban forest has greater structural variability than commercial and industrial areas (Dorney et al. 1984), and is thus more challenging to characterize with respect to urbanization. Knowledge of fine-scale residential urban forest patterns can improve our understanding of urban ecosystem dynamics by isolating individual landowner preferences and behaviors within a broader social and environmental context (Grove et al. 2006; Boone et al. 2010; Greene, Millward, and Ceh 2011). 
As the smallest coherent unit of land management, the property parcel scale is appropriate for assessing ecological effects of land use (Stone 2004; Manson et al. 2009). Given the importance of residential land in understanding metropolitan urban forest structure, this study is restricted to residential properties.

This article advances environmental geography by addressing two central questions regarding the effects of urbanization on urban forest structure. First, do patterns in urban forest structure vary along an urbanization gradient at the fine-scaled resolution of residential parcels? Apparent parcel-scale patterns would support the idea that urbanization intensity influences urban forest structure, while an absence of parcel-scale patterning would point to the overriding importance of other factors such as broader-scale cultural preferences, policy controls, or climatic influences. Second, can a character-based synthetic gradient outperform a distancebased gradient in identifying relationships between urbanization and urban forest structure at the property parcel scale? To address these questions, we generated both a character-based gradient using factor analysis and a standard distance-based gradient using Euclidean metrics, and then related urban forest data to both gradients to determine which one better explained urban forest structure. While this study draws on previous studies that have defined character-based urbanization gradients, this is among the first attempts to take the crucial next step of relating a character-based gradient to ecological structure. To our knowledge, it is also the first study to define a character-based gradient at the fine scale of property parcels. In doing so, this work generates new perspectives on emerging methodologies, contributes to urban ecological theory, and provides practical knowledge of urban forest structure at a fundamental scale of urban land management. 


\section{METHODS}

\section{Study Area}

The study area is a transect— $40 \mathrm{~km}$ long by $3 \mathrm{~km}$ wide_-located in Minnesota's Twin Cities Metropolitan Area (TCMA; Figure 1). This area is ideal for examining the relationships between urbanization and ecological structure because it exemplifies the growth of the Northern Midwest region of the United States, where urban land area is projected to increase by slightly more than the national average of 79 percent between 1997 and 2025 (Alig, Kline, and Lichtenstein 2004). The northern end of the transect is positioned in the urban core in the heart of downtown Minneapolis, the region's principal urban center. As the transect passes through the municipalities of Minneapolis, Richfield, Bloomington, Burnsville, Apple Valley, Lakeville, and Eureka Township, it generally transitions from urban to rural land cover types. This transect location was selected to capture a full range of urbanization intensities, include a wide variety of land cover types, minimize the occurrence of water bodies, and maintain consistent geospatial data availability. The Minnesota River runs through the transect near its center, and the transect contains a small portion of the Minneapolis-St. Paul International Airport property (see Ft. Snelling in Figure 1).

The study area is located within the $7,705 \mathrm{~km}^{2}$ seven-county TCMA, which had a 2010 population of 2.85 million (U.S. Census Bureau). The study municipalities had a combined 2010 population of 667,618 , and over half of those people resided in Minneapolis at the northern, most urban end of the transect (Table 1). In general, the oldest homes in the study were located in Minneapolis, and house age decreased with distance from the urban core (Table 1). Ongoing urbanization is concentrated toward the peri-urban fringe in the southern reaches of the transect, where new developments are primarily replacing treeless agricultural fields. This study was 
restricted to residential properties, which made up 51.7 percent of the study region by land area.

\section{Field Data}

This study used both field and digital data sets to assess urban forest attributes and land cover along the study transect. From May to August 2009, we collected field data at 150 residential parcels randomly selected from 2008 county property tax databases. Multiple-use properties were only eligible for inclusion if their primary use was residential. When sampling permission was denied at one residence, we replaced it at random with a site in the same municipality to ensure fair spatial representation across the study transect.

We sampled study sites for tree and woody shrub attributes. Site sampling followed the protocol for i-Tree Eco (Nowak et al. 2008; i-Tree Eco 2011), a USDA Forest Service model that has been widely applied in urban forestry research to quantify urban forest attributes and estimate associated ecosystem service values (Yang et al. 2005; Escobedo et al. 2008; Nowak et al. 2008). While i-Tree Eco was not used here to estimate ecosystem service values, its well accepted sampling procedure was appropriate for meeting the study objectives. Following i-Tree Eco protocol, trees were defined as any woody vegetation $>2.54 \mathrm{~cm}(1 \mathrm{in}$.) diameter at breast height (1.37 m; DBH). Shrubs were defined as woody vegetation $>30.48 \mathrm{~cm}(1 \mathrm{ft}$.$) tall and <2.54$ cm DBH. For each parcel, we recorded the standard i-Tree Eco measurements, which were used to generate the per-parcel urban forest variables for this study (Table 2). These included measures of tree distribution, tree size, woody shrub cover and abundance, municipal tree management, and opportunity for expanded tree cover. Most i-Tree studies are based on uniform circular plots, but we modified this approach and sampled 150 entire property parcels to better compare individual parcel characteristics to urban forest structure. 
We also estimated site impervious surface cover in the field, and later checked field estimates within a GIS against air photo estimates using $1 \mathrm{~m}$ resolution imagery from the National Agricultural Imagery Program for 2009 (http://datagateway.nrcs.usda.gov/). For the eighteen sites where field and GIS-based impervious surface estimates disagreed by more than 5 percent, estimates were adjusted by averaging. Once field data were collected for all 150 residential parcels, the urban forest attributes were associated with parcels within a geographic information system (GIS).

\section{Digital Data}

We used digital spatial data to define the urbanization gradient. For each study parcel, we derived nineteen urbanization indicators (Table 3). Most indicators were chosen because they were previously employed to characterize urbanization gradients (Hahs and McDonnell 2006; du Toit and Cilliers 2011). In fact, four measures_index_census_tract, index_image_100ha, index_combined, and pop_urb_land—-have recently been introduced to improve definition of character-based urbanization gradients (Weeks 2003; Hahs and McDonnell 2006). Depending on the spatial data available, urbanization indicators were derived for individual study sites at the scale of the parcels themselves, at the U.S. Census tract, or within a 100 ha neighborhood. Pop_density and pop_urb_land were calculated at the U.S. Census tract level because more detailed data were not available. Census tracts are "designed to be homogeneous with respect to population characteristics, economic status, and living conditions" (U.S. Census Bureau), so their use was appropriate for characterizing neighborhoods in this study. The 100 ha neighborhood was defined as a circular buffer around each parcel centroid, and was employed for two reasons:

(1) Minneapolis neighborhoods within the study area average approximately 120 ha, so 100 ha is 
within the same order of magnitude and reasonably approximates neighborhood size; and perhaps more importantly, (2) neighborhood variables were highly correlated at various spatial scales, so choosing a single scale did not bias results substantially. To assess any such effect, we calculated each neighborhood variable using 10,25, 100, and 250 ha buffers around the centroids. We then scaled each variable by a factor to yield 100 ha equivalents, and assessed linear correlations between 100 ha buffers and each of the other buffer distances (Figure 2). Since all correlations were highly significant $(p<0.001)$, we only used 100 ha neighborhoods for simplicity.

Digital spatial data were collected from several sources. Parcel data for the year 2008 were acquired from the Metropolitan Council (http://www.metrocouncil.org/), and included parcel size, value, and house age. A 2007 land cover classification, obtained from the University of Minnesota's Remote Sensing and Geospatial Analysis Laboratory (http://land.umn.edu), was the basis for landscape metrics and neighborhood impervious surface estimates. This classification is based on $30 \mathrm{~m}$ resolution Landsat imagery, has an assessed accuracy $>93$ percent, and contains the following five classes: agriculture, forest, urban, water, and wetland/shrubland/grassland. It also includes an impervious surfaces classification under the urban class only, which is based on the inverse relationship between impervious surfaces and the "greenness" component of a tasseled cap transformation (Bauer, Loffelholz, and Wilson 2008). Impervious surfaces are mapped as a percentage of each $30 \mathrm{~m}$ Landsat pixel. Finally, roads and population data were obtained from the U.S. Census TIGER data set (http://www.census.gov/geo/www/tiger/). Landscape metrics were calculated in Fragstats 3.3 (McGarigal et al. 2002), while all other GIS processes were completed in ArcGIS 10 (ESRI 2010). 


\section{Analysis}

We conducted two analyses to assess urban forest structure along the urban-rural gradient. In the first, we compared urban forest structure to a simple distance-based gradient to emulate classic urban environmental studies. In the second, we related urban forest structure to a more sophisticated character-based gradient. We used the same variables for both analyses, and variables were transformed as necessary to meet assumptions of linearity and normality for each method (Tables 2 and 3). The full data set included fourteen urban forest structural attributes (Table 2) and nineteen urbanization indicators (Table 3). The data set had no missing values over the 150 samples.

For the first analysis, assessing the distance-based gradient's relationship to urban forest structure, we used regression analysis to separately test the association between the logarithm of urban_distance and each urban forest structural attribute. Because urban forest structure does not necessarily exhibit linear responses to urban-rural distance (Berland 2012), we tested for significant linear and curvilinear relationships using polynomial regression models. We estimated linear, quadratic, and cubic regression models, and used $F$-tests to determine whether enhanced curve fitting afforded by a higher polynomial was statistically worth the reduction in degrees of freedom (after Walford 2011). In the end, we evaluated which curve, if any, best described urban-rural distance trends for each urban forest attribute. We corrected significance values for multiple simultaneous hypothesis tests with a false discovery rate adjustment (Benjamini and Hochberg 1995; Verhoeven, Simonsen, and McIntyre 2005; Pike 2011).

For the second analysis, we related urban forest structure to a character-based urbanization gradient. This analysis drew on foundational research in defining character-based 
gradients with data dimension reducing techniques. In 2006, Hahs and McDonnell used principal components analysis to isolate the variables that best explained non-redundant variability in a large set of urbanization indicators. Principal components analysis reduces data dimensionality within multicollinear data sets by generating linear combinations of input variables to maximize the total data set variability explained. Du Toit and Cilliers (2011) argued that factor analysis, as compared to principal components analysis, provides a more appropriate means of reducing dimensionality in large urbanization data sets, because factor analysis only accounts for variance that is shared by multiple variables and excludes variance unique to a single variable (Sheskin 2007). This allows factor analysis to more readily uncover latent variables, or underlying structures, in the data set that influence multiple urbanization indicator variables. The goal of factor analysis, then, is to derive a small set of factors that explain substantial trends within a large set of urbanization indicators.

We conducted factor analysis using principal axis factoring within the SPSS software package (IBM 2010). We started with the full set of nineteen urbanization indicators, but because factor analysis is sensitive to excessive multicollinearity, we iteratively removed individual variables until the determinant of the variable correlation matrix was greater than 0.00001 (Sheskin 2007). All factors with eigenvalues $>1$ were retained, as these account for more variance than would be expected of any one variable (Riitters et al. 1995; Sheskin 2007). The urbanization indicator variables with loadings $>0.71$ were used to interpret the trends represented in each factor, as this benchmark represents 50 percent overlapping variance between the variable and the factor (du Toit and Cilliers 2011). Varimax rotation was used to enhance factor interpretability.

Factor analysis holds great promise for efficiently deriving urbanization gradients from 
complex assemblages of variables, but it is only one step toward understanding the relationships between urbanization gradients and ecological characteristics, given that the nature, direction, and magnitude of these relationships remain largely unknown. We used forward stepwise polynomial regression to take the next step of relating the urbanization gradient to urban forest structure. Specifically, we related transformed urban forest structural variables individually to the retained urbanization gradient factors. Forward stepwise polynomial regression is an extension of linear regression that facilitates testing for linear and curvilinear urban foresturbanization relationships among all retained urbanization factors simultaneously. Urbanization factors providing significant improvements in the regression model (i.e., those yielding $F$-test $p$ values $<0.05$ ) were entered into the model in order of explanatory power. This approach ensured that we considered all key urbanization trends relating strongly to each urban forest structural attribute. We related urban forest structure directly to factor scores for each urbanization factor. While one common approach is to use the variable with the highest loading to represent each factor (e.g., Riitters et al. 1995; Hahs and McDonnell 2006; du Toit and Cilliers 2011), we were attempting to relate urban forest structure to underlying trends in the urbanization data set, so using factor scores offered the benefit of representing latent trends in the urbanization gradient that any single indicator variable could not capture on its own. Once again, we applied a false discovery rate adjustment to $p$-values to offset the potential impact of multiple testing (Benjamini and Hochberg 1995; Verhoeven, Simonsen, and McIntyre 2005; Pike 2011). Outliers, defined as observations with Studentized residuals exceeding \pm 3.00 , were removed from each analysis. We used Moran's I statistic to test for spatial autocorrelation among regression residuals. 


\section{RESULTS}

We compiled urban forest variables and urbanization indicator variables for 150 sampled residential parcels. See Tables 2 and 3 for each variable's minimum, maximum, and median values. These variables were used to relate the distance- and character-based gradients to urban forest structure.

In the first step of the analysis, we examined the distance-based gradient and found that 64.3 percent $(n=9 / 14)$ of the urban forest structural variables were explained by the gradient (Table 4). Note that many urban forest response variables were dependent on one another (e.g., tree_count and trees_ha; tree_ht_median and $C B \_h t$ median), so the total number of urban forest structural variables explained is less important than the number of structural categories explained. The simple distance-based gradient explained variables in the structural categories of tree size (e.g., basal_area and DBH_max), shrub abundance, and municipal street tree abundance, but did not explain measures of tree distribution and expansion potential. Curvilinear regression curves provided better fits than linear regression curves for 55.6 percent $(n=5 / 9)$ of the significant relationships. For urban forest structural attributes best explained by linear regression (e.g., shrub_cover), structural values decreased with increasing distance from the urban core. For urban forest structural attributes best explained by curvilinear regression (e.g., basal_area), structural values peaked at intermediate distances from the urban core.

The second step of the analysis examined a character-based urbanization gradient. In deriving the gradient using factor analysis, we excluded seven of the nineteen candidate urbanization indicators due to high multicollinearity (Table 5). Using the remaining twelve urbanization indicators, we identified two factors explaining 65.50 percent of the shared variance in the data set (Table 5). Each factor had at least five variables with factor loadings greater than 
\pm 0.50 , so we were satisfied that factors were not extracted on the basis of a single correlation (after du Toit and Cilliers 2011). Factor 1 explained 33.90 percent of the shared variance, and was most closely associated with urban_distance and imperv_100ha. Factor 2 explained 31.60 percent of the shared variance, and was most closely associated with dwellings_100ha and index_census_tract. Figure 3 shows the spatial structure of each factor. The Pearson productmoment correlation between factors 1 and 2 was $-0.044(p=0.591)$, indicating that the factors described fundamentally different trends in the urbanization indicator data set.

Stepwise polynomial regression highlighted significant relationships between the urbanization factors and nine urban forest structural attributes (Table 6). Eight (88.9 percent) of these structural attributes were previously related to the distance-based urbanization gradient. The character-based gradient differed from the distance-based gradient by explaining significant variation in tree_cover, and by failing to explain variation in $D B H$ median. Tree_cover was the only variable explained by factor 2 alone, and urbanization's relationship with basal_area was better explained by considering both factors. Most urban forest structural variables were positively associated with urbanization intensity, but two quadratic relationships_- $D B H \_$max and tree_ht_max_-peaked at intermediate urbanization intensities (Table 6). Spatially autocorrelated residuals were not observed for any of the regression analyses per a Moran's $I$ test and visual inspection for clustering.

\section{DISCUSSION}

\section{Urban forest structure relates to urbanization gradients}

We analyzed the relationship between urban forest structure and two urbanization gradient characterizations, namely distance-based and character-based. The former showed that parcel 
location relative to the urban core can explain trends in tree size, shrub abundance, and tree management. However, this gradient did not relate well to any measure of tree distribution, most notably tree_cover. While tree canopy cover may provide a limited view of the urban forest (Kenney, van Wassenaer, and Satel 2011), it is nonetheless a primary metric for assessing urban forest quantity, spatial distribution, and associated management goals (Nowak et al. 1996; Walton, Nowak, and Greenfield 2008; McPherson et al. 2011). Given the significance of canopy cover in urban forest assessment and management, the inability to describe canopy cover with a simple distance-based gradient justified the use of more sophisticated character-based gradients.

Using factor analysis to derive a character-based gradient was valuable in that it synthesized two primary trends in the urbanization indicator data set. Factor 1 showed a very strong urban-rural distance pattern (Figure 3), and thus evidenced many of the same relationships to urban forest structure seen in the distance-based gradient analysis (Tables 4 and 6). While factor 1 was also influenced by urbanization indicators such as imperv_100ha (Table 5), it is apparent that urban-rural distance best described the primary urbanization trend in the study area. Factor 2 was most strongly associated with dwellings_100ha, indicating a more nuanced urbanization trend from highly residential to non-residential neighborhoods. Note that nonresidential neighborhoods were found at both the urban core and peri-urban fringe (Figure 3), highlighting the fact that key trends in an urbanization data set may not reflect urbanization intensity in the traditional sense. The residential neighborhood density trend was pertinent here because landscape context may affect urban forest structure via physical space for planting trees, housing age and lagged tree growth, landowner demographics, and neighborhood group identity (Grove et al. 2006; Boone et al. 2010; McPherson et al. 2011; Berland 2012).

In addition to drawing out broad urbanization trends, the character-based gradient 
captured trends in tree_cover via its consideration of residential density; these patterns were not detected using the simple distance-based gradient. By extending explanatory power to the tree distribution category, the character-based gradient derived using factor analysis offered a key improvement over the distance-based gradient. This enhancement in explanatory power suggests that using factor analysis or related methods to derive character-based gradients is worthwhile when studying the impacts of urbanization on ecological structure. That said, aside from describing tree_cover, insights gleaned from the factor analysis approach were similar to those taken from the distance-based analysis given the strong association of urban_distance with factor 1. This similarity in gradients suggests that urban-rural distance is adequate to describe basic urbanization-urban forest structural relationships, but considering the increasing availability of geospatial data and growing interest in urban ecological structure, factor analysis and related approaches should continue to be refined and employed to search for patterns within and among metropolitan areas.

Both the distance-based and character-based urbanization gradients emphasized the importance of curvilinear relationships between urbanization and urban forest structure (Tables 4 and 6). Many urban forest attributes, particularly those associated with tree size, peaked at intermediate urbanization intensities. The primary cause is likely that older inner-ring suburbs had the tree maturation time and physical space to attain the largest tree sizes (Berland 2012), but more complicated factors may also be involved. On the oldest properties near the urban core, which were developed over one hundred years ago, the first generation of planted trees may have died and been replaced by smaller trees, while the original tree plantings in Richfield and Bloomington persisted at fully mature sizes because they were planted more recently. Since urban development in this region largely replaced agricultural fields, there were few existing 
trees prior to development, and trees planted in newer suburbs have yet to reach mature sizes.

Such temporal lag effects are of growing interest in urban ecology (Ramalho and Hobbs 2012).

Urban planning and municipal urban forest management may also explain peak tree sizes in inner-ring suburbs, as older neighborhoods were planted to achieve a tree canopy over the narrow streets, while newer suburbs contained more ornamental and coniferous trees not conducive to creating substantial tree canopies. Several urban Minneapolis study parcels were recently converted from large single-family homes to apartments or townhomes, and this redevelopment favored small ornamental trees, potentially at the expense of large, mature trees. The near-urban municipalities of Minneapolis, Richfield, and Bloomington have also historically had the most active city tree planting programs (see street_trees in Table 6), whereas newer suburbs have less predictable tree cover due to increased landowner choice. Finally, biological factors such as Dutch elm disease (Ophiostoma spp.) may have substantially reduced the abundant mature American elm (Ulmus americana) trees in Minneapolis, while sparing common mature species in Richfield and Bloomington, most notably silver maple (Acer saccharinum) and Norway maple (Acer platanoides). Tracking tree sizes and urban forest management strategies through time along the urbanization gradient could help explain varying urban forest structure among municipalities by showing where, when, and why these changes occur.

\section{Considerations for relating urbanization gradient factors to ecological structure}

Character-based urbanization gradients show promise for demonstrating the effects of urbanization on ecological structure. This research supports Hahs and McDonnell (2006) in that data dimensionality reducing techniques provide an effective approach to objectively selecting a small set of measures to define urbanization gradients, yet we suggest careful consideration of 
four key qualifications. First, when attempting to represent underlying urbanization factors using a combination of urbanization indicator variables, factor analysis may be more appropriate than principal components analysis because it emphasizes shared variance to identify those latent factors that cannot be captured by one indicator variable alone (du Toit and Cilliers 2011). Principal components analysis, on the other hand, is susceptible to the effects of specific variance in one indicator variable that is completely unrelated to the other variables (Sheskin 2007).

Second, although factor analysis provides an appropriate technique for identifying latent urbanization factors, it is important to avoid excessive multicollinearity because factor analysis can be sensitive to the shared variance among many highly correlated input variables. A useful heuristic is to iteratively remove input variables until the determinant of the variable correlation matrix is greater than 0.00001 (Sheskin 2007). Failure to properly implement data reduction techniques may lead to faulty conclusions when relating urbanization factors to ecological structure. When factor analysis was applied to our data prior to reducing multicollinearity, four landscape metrics including Simpson_LC_100ha, LSI_100ha,LPI_100ha, and patches_100ha determined the first factor because they were highly multicollinear. Following the statistically appropriate exclusion of some landscape metrics from the factor analysis, more intuitive urbanization indicators (i.e., urban_distance and imperv_100ha) characterized the primary urbanization trend.

Third, it may be preferable to relate ecological structure directly to the factor scores associated with each urbanization factor. Past work has suggested using the variable with the highest loading on each factor to represent that factor (Riitters et al. 1995; Hahs and McDonnell 2006; du Toit and Cilliers 2011). However, the main point of using factor analysis is to identify latent factors that no single urbanization indicator can fully capture, so the best approximation of 
that factor (i.e., factor scores) should be used to represent it. One potential difficulty in using the factors themselves to describe urbanization trends is a lack of interpretability, but in our analysis factor rotation enhanced interpretability so that we could describe the primary trends of urbanrural distance and residential neighborhood density.

Finally, factor analysis can identify major trends in an urbanization data set, but it cannot determine whether those trends are ecologically relevant (Riitters et al. 1995; du Toit and Cilliers 2011). At the same time, if additional variables are incorporated ad hoc following factor analysis, then the original goal of objectively indentifying major latent urbanization trends to explain ecological structure is compromised. In our analysis, house_age was not closely associated with either urbanization factor, so it exerted only a weak influence on the factors used in the regression models predicting urban forest structure. However, house_age does influence urban forest structure (Grove et al. 2006; Berland 2012), so its inclusion could potentially help explain urban forest structural patterns. The tradeoffs between objectivity and subjectively identifying ecologically relevant urbanization indicators should be explored further in the future.

\section{Limitations, uncertainty, and future opportunities}

Although this research supports the development of character-based urbanization gradients to assess urban forest structure, some limitations warrant consideration. For example, by focusing solely on residential land at the parcel scale, we did not assess patterns on non-residential lands or at broader spatial scales, although as argued above, this focus was driven by the distinct need for fine-scale analysis of private residential land. There may be error attributable to spatial data sets, field data collection, or data input, but no systematic biases were discovered during analysis. The decision to base neighborhood urbanization variables on 100 ha buffers was 
supported by robust variable scaling across multiple buffer distances (Figure 2), but it is unknown how this decision affected individual study parcels. Some variables were estimated at five percent intervals per i-Tree sampling protocol (i-Tree Eco 2011), and there is no straightforward approach for quantifying the effects of this estimation strategy on study findings. The fairly coarse land cover data set (30 m spatial resolution, five land cover classes) may have influenced the landscape metrics used as urbanization indicators (Wickham and Riitters 1995; Wu et al. 2002), but these data were used to calculate land use and urbanization indices at the scale of 100 ha, which is three orders of magnitude greater than the pixel size. Spatial errors in the underlying data would therefore lead to very small variations in the derived neighborhood measures. By the same token, the five attribute categories were explicitly chosen to capture urban land use, and struck a balance between the number of classes and the goal of creating data with high overall accuracy (Yuan 2008; Yuan, Wu, and Bauer 2008).

Some of the difficulty in predicting parcel-scale urban forest structure may stem from our reliance on neighborhood-scale urbanization indicators that describe patterns at scales much broader than the average parcel size. Although the available parcel data and field surveys provided several parcel-specific characteristics, more variables may be needed to improve analytical power. Since the parcel is the most basic unit of land management, improving parcelscale data collection methodologies may improve our ability to predict fine-scale urban forest structure. Improved parcel-scale data could, in turn, be used to model the emergent effects of individual land management decisions on neighborhood- or regional-scale urban forest structure.

Beyond limitations imposed by study design and input data, some urbanization-urban forest structural relationships may have simply been overlooked, because urban forest structure is subject to complex aspects of coupled human-environmental systems (Alberti et al. 2003; Liu 
et al. 2007). Tree growth is temporally lagged such that present day urban forest structure may not reflect urbanization intensity (Dow 2000; Grove et al. 2006; Dean 2011). Similarly, urban growth in this region largely replaced agricultural lands, and legacies of this primarily treeless past are evidenced in present urban forest structure (Berland 2012). Finally, emergent patterns in urban forest structure only evident at broad scales may arise from fine-scale urban forest management across many individual parcels. Continued analysis of urbanization's effects on ecological structure through time and across space will improve understanding of these complexities.

\section{CONCLUSIONS}

We used gradient analysis to study the relationships between urbanization and urban forest structure. A simple distance-based gradient captured trends in 64.3 percent $(n=9 / 14)$ of the urban forest attributes assessed, spanning measures of tree size, shrub abundance, and municipal tree management. We then used factor analysis to derive a gradient based on a suite of urbanization indicators, and extracted two key factors strongly related to urban-rural distance and residential neighborhood density, respectively. Like the distance-based gradient, the characterbased gradient explained 64.3 percent $(n=9 / 14)$ of the urban forest attributes, but it improved upon the distance-based gradient by adding tree distribution to the types of urban forest structural attributes explained. In addition, the character-based gradient provided a useful summative function in identifying the two key factors of urban-rural distance and residential neighborhood density. Many urban forest structural attributes peaked at intermediate degrees of urbanization, highlighting the need to consider curvilinear relationships in urban ecological settings. As this study is among the first to relate a character-based urbanization gradient to ecological structure, 
our findings are relevant to urban environmental geography in general, and urban forestry in particular. Continued advances in data availability and methodologies, along with better understanding of complex aspects of human-natural systems, will improve conceptualizations of how urbanization impacts ecological structure.

\section{ACKNOWLEDGMENTS}

This article is based upon work supported by the National Science Foundation under Grant No. 1003138, and by the University of Minnesota's Graduate School and College of Liberal Arts.

Brewster Malevich provided field assistance. The article was improved by comments from Tom Crist, Grant Elliott, anonymous referees, and the section editor. 


\section{REFERENCES}

Akbari, H., L. S. Rose, and H. Taha. 2003. Analyzing the land cover of an urban environment using high-resolution orthophotos. Landscape and Urban Planning 63: 1-14.

Alig, R. J., J. D. Kline, and M. Lichtenstein. 2004. Urbanization on the US landscape: looking ahead in the $21^{\text {st }}$ century. Landscape and Urban Planning 69: 219-234.

Alberti, M., J. M. Marzluff, E. Shulenberger, G. Bradley, C. Ryan, and C. Zumbrunnen. 2003. Integrating humans into ecology: opportunities and challenges for studying urban ecosystems. BioScience 53: 1169-1179.

Alberti, M., and L. Susskind. 1996. Managing urban sustainability: an introduction to the special issue. Environmental Impact Assessment Review 16: 213-221.

Bauer, M. E., B. C. Loffelholz, and B. Wilson. 2008. Estimating and mapping impervious surface area by regression analysis of Landsat imagery. In Remote Sensing of Impervious Surfaces, ed. Q. Weng, 3-19. Boca Raton, FL: CRC Press.

Benjamini, Y., and Y. Hochberg. 1995. Controlling the false discovery rate: a practical and powerful approach to multiple testing. Journal of the Royal Statistical Society B 57: 289300.

Berland, A. 2012. Long-term urbanization effects on tree canopy cover along an urban-rural gradient. Urban Ecosystems 15: 721-738.

Boone, C. G., M. L. Cadenasso, J. M. Grove, K. Schwarz, and G. L. Buckley. 2010. Landscape, vegetation characteristics, and group identity in an urban and suburban watershed: why the 60s matter. Urban Ecosystems 13:255-271.

Dean, J. 2011. The social production of a Canadian urban forest. In Environmental and Social Justice in the City: Historical Perspectives, eds. G. Massard-Guilbaud, and R. Rodger, 
67-88. Cambridge, UK: White Horse Press.

Dorney, J. R., G. R. Guntenspergen, J. R. Keough, and F. Stearns. 1984. Composition and structure of an urban woody plant community. Urban Ecology 8: 69-90.

Dow, K. 2000. Social dimensions of gradients in urban ecosystems. Urban Ecosystems 4: 255275.

du Toit, M. J., and S. S. Cilliers. 2011. Aspects influencing the selection of representative urbanization measures to quantify urban-rural gradients. Landscape Ecology 26: 169-181.

Dwyer, J. F., E. G. McPherson, H. W. Schroeder, and R. A. Rowntree. 1992. Assessing the benefits and costs of the urban forest. Journal of Arboriculture 18: 227-234.

Escobedo, F. J., J. E. Wagner, D. J. Nowak, C. Luz De la Maza, M. Rodriguez, and D. E. Crane. 2008. Analyzing the cost effectiveness of Santiago, Chile's policy of using urban forests to improve air quality. Journal of Environmental Management 86: 148-157.

ESRI. 2010. ArcGIS 10.0. Redlands, CA, USA.

Greene, C. S., A. A. Millward, and B. Ceh. 2011. Who is likely to plant a tree? The use of public socio-demographic data to characterize client participants in a private urban forestation program. Urban Forestry \& Urban Greening 10: 29-38.

Grove, J. M., A. R. Troy, J. P. O’Neil-Dunne, W. R. Burch, M. L. Cadenasso, and S. T. A. Pickett. 2006. Characterization of households and its implications for the vegetation of urban ecosystems. Ecosystems 9: 578-597.

Hahs, A. K., and M. J. McDonnell. 2006. Selecting independent measures to quantify Melbourne's urban-rural gradient. Landscape and Urban Planning 78: 435-448.

IBM. 2010. IBM SPSS Statistics 19. Armonk, NY, USA. 
i-Tree Eco. 2011. i-Tree Eco User's Manual. URL: http://itreetools.org/resources/manuals.php (last accessed 22 December 2012).

Kenney, W. A., P. J. E. van Wassenaer, and A. L. Satel. 2011. Criteria and indicators for strategic urban forest planning and management. Arboriculture \& Urban Forestry 37: $108-117$.

Liu, J., T. Dietz, S. R. Carpenter, M. Alberti, C. Folke, E. Moran, A. N. Pell, P. Deadman, T. Kratz, J. Lubchenco, E. Ostrom, Z. Ouyang, W. Provencher, C. L. Redman, S. H. Schneider, and W. W. Taylor. 2007. Complexity of coupled human and natural systems. Science 317: 1513-1516.

Manson, S. M., H. A. Sander, D. Ghosh, J. M. Oakes, M. W. Orfield, W. J. Craig, T. F. Luce, Jr., E. Myott, and S. Sun. 2009. Parcel data for research and policy. Geography Compass 3: 698-726.

McDonnell, M. J., and A. K. Hahs. 2008. The use of gradient analysis studies in advancing our understanding of the ecology of urbanizing landscapes: current status and future directions. Landscape Ecology 23: 1143-1155.

McDonnell, M. J., and S. T. A. Pickett. 1990. Ecosystem structure and function along urbanrural gradients: an unexploited opportunity for ecology. Ecology 71: 1232-1237.

McDonnell, M. J., S. T. A. Pickett, P. Groffman, P. Bohlen, R. V. Pouyat, W. C. Zipperer, R. W. Parmelee, M. M. Carreiro, and K. Medley. 1997. Ecosystem processes along an urban-torural gradient. Urban Ecosystems 1:21-36.

McGarigal, K., S. A. Cushman, M. C. Neel, and E. Ene. 2002. FRAGSTATS 3.3: Spatial Patterns Analysis Program for Categorical Maps. Amherst, MA, USA. 
McPherson, E. G. 1998. Structure and sustainability of Sacramento's urban forest. Journal of Arboriculture 24: 174-190.

McPherson, E. G., D. Nowak, G. Heisler, S. Grimmond, C. Souch, R. Grant, and R. Rowntree. 1997. Quantifying urban forest structure, function, and value: the Chicago Urban Forest Climate Project. Urban Ecosystems 1: 49-61.

McPherson, E. G., J. R. Simpson, Q. Xiao, and C. Wu. 2011. Million trees Los Angeles canopy cover and benefit assessment. Landscape and Urban Planning 99: 40-50.

Medley, K. E., M. J. McDonnell, and S. T. A. Pickett. 1995. Forest-landscape structure along an urban-to-rural gradient. The Professional Geographer 47: 159-168.

Nowak, D. J., D. E. Crane, J. C. Stevens, R. E. Hoehn, J. T. Walton, and J. Bond. 2008. A ground-based method of assessing urban forest structure and ecosystem services. Arboriculture \& Urban Forestry 34: 347-358.

Nowak, D.J., and J.F. Dwyer. 2007. Understanding the benefits and costs of urban forest ecosystems. In Urban and Community Forestry in the Northeast, ed. J.E. Kuser, 25-46. New York: Springer.

Nowak, D. J., M. H. Noble, S. M. Sisinni, and J. F. Dwyer. 2001. People \& trees: assessing the US urban forest resource. Journal of Forestry 99: 37-42.

Nowak, D. J., R. A. Rowntree, E. G. McPherson, S. M. Sisinni, E. R. Kerkmann, and J. C. Stevens. 1996. Measuring and analyzing urban tree cover. Landscape and Urban Planning 36: 49-57.

Pike, N. 2011. Using false discovery rates for multiple comparisons in ecology and evolution. Methods in Ecology and Evolution 2: 278-282. 
Porter, E. E., B. R. Forschner, and R. B. Blair. 2001. Woody vegetation and canopy fragmentation along a forest-to-urban gradient. Urban Ecosystems 5: 131-151.

Ramalho, C. E., and R. J. Hobbs. 2012. Time for a change: dynamic urban ecology. Trends in Ecology \& Evolution 27: 179-188.

Riitters, K. H., R. V. O’Neill, C. T. Hunsaker, J. D. Wickham, D. H. Yankee, S. P. Timmins, K. B. Jones, and B. L. Jackson. 1995. A factor analysis of landscape pattern and structure metrics. Landscape Ecology 10: 23-39.

Sheskin, D. J. 2007. Handbook of Parametric and Nonparametric Statistical Procedures, $4^{\text {th }}$ edition. Boca Raton, FL: Chapman \& Hall.

Stone, B., Jr. 2004. Paving over paradise: how land use regulations promote residential imperviousness. Landscape and Urban Planning 69: 101-113.

U.S. Census Bureau. American FactFinder. URL: http://factfinder2.census.gov (last accessed 22 December 2012).

Verhoeven, K. J. F., K. L. Simonsen, and L. M. McIntyre. 2005. Implementing false discovery rate control: increasing your power. Oikos 108: 643-647.

Walford, N. 2011. Practical Statistics for Geographers and Earth Scientists. Chichester, UK: Wiley-Blackwell.

Walton, J. T., D. J. Nowak, and E. J. Greenfield. 2008. Assessing urban forest canopy cover using airborne or satellite imagery. Arboriculture \& Urban Forestry 34: 334-340.

Wang, H., Q. He, X. Liu, Y. Zhuang, and S. Hong. 2012. Global urbanization research from 1991 to 2009: A systematic research review. Landscape and Urban Planning 104: 299309. 
Weeks, J. R. 2003. Using remote sensing and geographic information systems to identify the underlying properties of urban environments. In New Forms of Urbanization: Beyond the Urban-Rural Dichotomy, eds. T. Champion, and G. Hugo, 323-343. Aldershot, UK: Ashgate Publishing.

Wickham, J. D., and K. H. Riitters. 1995. Sensitivity of landscape metrics to pixel size. International Journal of Remote Sensing 16: 3585-3594.

Williams, N. S. G., M. W. Schwartz, P. A. Vesk, M. A. McCarthy, A. K. Hahs, S. E. Clemants, R. T. Corlett, R. P. Duncan, B. A. Norton, K. Thompson, and M. J. McDonnell. 2009. A conceptual framework for predicting the effects of urban environments on floras. Journal of Ecology 97: 4-9.

Wu, J. G., W. J. Shen, W. Z. Sun, and P. T. Tueller. 2002. Empirical patterns of the effects of changing scale on landscape metrics. Landscape Ecology 17: 761-782.

Yang, J., J. McBride, J. Zhou, and Z. Sun. 2005. The urban forest in Beijing and its role in air pollution reduction. Urban Forestry \& Urban Greening 3: 65-78.

Yuan, F. 2008. Land cover change and environmental impact analysis in the Greater Mankato area of Minnesota using remote sensing and GIS modeling. International Journal of Remote Sensing 29: 1169-1184.

Yuan, F., K. E. Sawaya, B. C. Loeffelholz, and M. E. Bauer. 2005. Land cover classification and change analysis of the Twin Cities (Minnesota) Metropolitan Area by multitemporal Landsat remote sensing. Remote Sensing of Environment 98: 317-328.

Yuan, F., C. Wu, and M. E. Bauer. 2008. Comparison of various spectral analytical techniques for impervious surface estimation using Landsat imagery. Photogrammetric Engineering and Remote Sensing 74: 1045-1055. 
Table 1. Study area municipality characteristics

\begin{tabular}{lccccr}
\hline Municipality & $\begin{array}{c}\text { Area in } \\
\text { transect }\left(\mathrm{km}^{2}\right)\end{array}$ & $\begin{array}{c}\text { \% of } \\
\text { transect area }\end{array}$ & $\begin{array}{c}\text { Pop density } \\
\left(\text { people } / \mathrm{km}^{2}\right)^{\mathrm{a}}\end{array}$ & $\begin{array}{c}\text { Median house } \\
\text { age (years) }\end{array}$ & $\begin{array}{c}\text { Study } \\
\text { sites }\end{array}$ \\
\hline Minneapolis & 27.89 & 23.24 & $2,574.12$ & 85 & 58 \\
Richfield & 7.79 & 6.49 & $1,953.96$ & 56 & 19 \\
Ft. Snelling (Airport) & 2.61 & 2.18 & 7.42 & NA & 0 \\
Bloomington & 16.98 & 14.15 & 834.61 & 54 & 22 \\
Burnsville & 27.88 & 23.23 & 863.06 & 30 & 24 \\
Apple Valley & 3.29 & 2.74 & $1,084.80$ & 22 & 2 \\
Lakeville & 28.89 & 24.08 & 572.00 & 16 & 23 \\
Eureka Township & 4.67 & 3.89 & 15.38 & 6 & 2 \\
Total & 120.00 & 100.00 & $1,128.26$ & 55 & 150 \\
\hline
\end{tabular}

${ }^{\mathrm{a}}$ Municipality value, not necessarily representative of land within study transect (Source: U.S. Census Bureau 2010).

${ }^{\mathrm{b}}$ Study site house ages calculated as 2009 minus year of construction. 
Table 2. Description of urban forest structural attributes

\begin{tabular}{|c|c|c|c|c|c|}
\hline \multirow{2}{*}{$\frac{\text { Variable }}{\text { Tree distribution }}$} & \multirow[t]{2}{*}{ Description } & \multirow[t]{2}{*}{ Min } & Max & Median & Transformation \\
\hline & & & & & \\
\hline tree_cover & $\begin{array}{l}\text { Percent of parcel area covered by tree canopies. Estimated } \\
\text { in the field at } 5 \text { percent intervals per i-Tree protocol. }\end{array}$ & 3 & 83 & 28 & $\log$ \\
\hline tree count & Total trees $(>2.54 \mathrm{~cm} \mathrm{DBH})$ on the property parcel. & 1 & 137 & 6 & $\log$ \\
\hline trees_ha & Trees per hectare. & 6.18 & 343.41 & 53.97 & Log \\
\hline \multicolumn{6}{|l|}{ Tree size } \\
\hline basal_area & $\begin{array}{l}\text { Cross-sectional area of all tree stems in the parcel } \\
\text { standardized by parcel area }\left(\mathrm{m}^{2} / \mathrm{ha}\right) \text {. }\end{array}$ & 0.01 & 25.05 & 5.84 & Arcsinh \\
\hline DBH_median & Median DBH $(\mathrm{cm})$ for all trees on the parcel. & 4.7 & 104.3 & 25.9 & Log \\
\hline DBH_max & $\begin{array}{l}\text { Maximum DBH }(\mathrm{cm}) \text { for all trees on the parcel. For } \\
\text { individual trees with multiple stems, DBH is summed for } \\
\text { up to the } 6 \text { largest stems. }\end{array}$ & 6.2 & 239 & 67.6 & Log \\
\hline tree_ht_median & Median tree height $(\mathrm{m})$ for all trees on the parcel. & 2 & 14 & 6 & Sqrt \\
\hline tree_ht_max & Maximum tree height (m). & 2 & 17 & 10 & Sqrt \\
\hline CB_ht_median & Median height to crown base (m). & 0 & 8 & 2 & Arcsinh \\
\hline \multicolumn{6}{|l|}{ Shrub abūndance } \\
\hline shrub_cover & $\begin{array}{l}\text { Percent of parcel area covered by shrubs. Estimated in the } \\
\text { field at } 5 \text { percent intervals per i-Tree protocol. }\end{array}$ & 0 & 43 & 8 & Arcsine \\
\hline shrub_count & $\begin{array}{l}\text { Total shrub species on the property parcel, limited to } \\
\text { twelve per i-Tree protocol. }\end{array}$ & 0 & 12 & 5 & Arcsinh \\
\hline shrubs_ha & Shrub species per hectare. & 0 & 196.63 & 40.83 & Arcsinh \\
\hline \multicolumn{6}{|l|}{ Management } \\
\hline street_trees & $\begin{array}{l}\text { Percent of parcel trees maintained municipally in the street } \\
\text { right-of-way. }\end{array}$ & 0 & 100 & 0 & Arcsine \\
\hline \multicolumn{6}{|l|}{ Expansion potential } \\
\hline plantable_space & $\begin{array}{l}\text { Percent of parcel unoccupied by tree canopies where trees } \\
\text { could grow. }\end{array}$ & 0 & 78 & 30.5 & Arcsine \\
\hline
\end{tabular}

All variables were measured at the property parcel scale for 150 residences. $\mathrm{DBH}=$ diameter at breast height. 
Table 3. Description of urbanization indicator variables

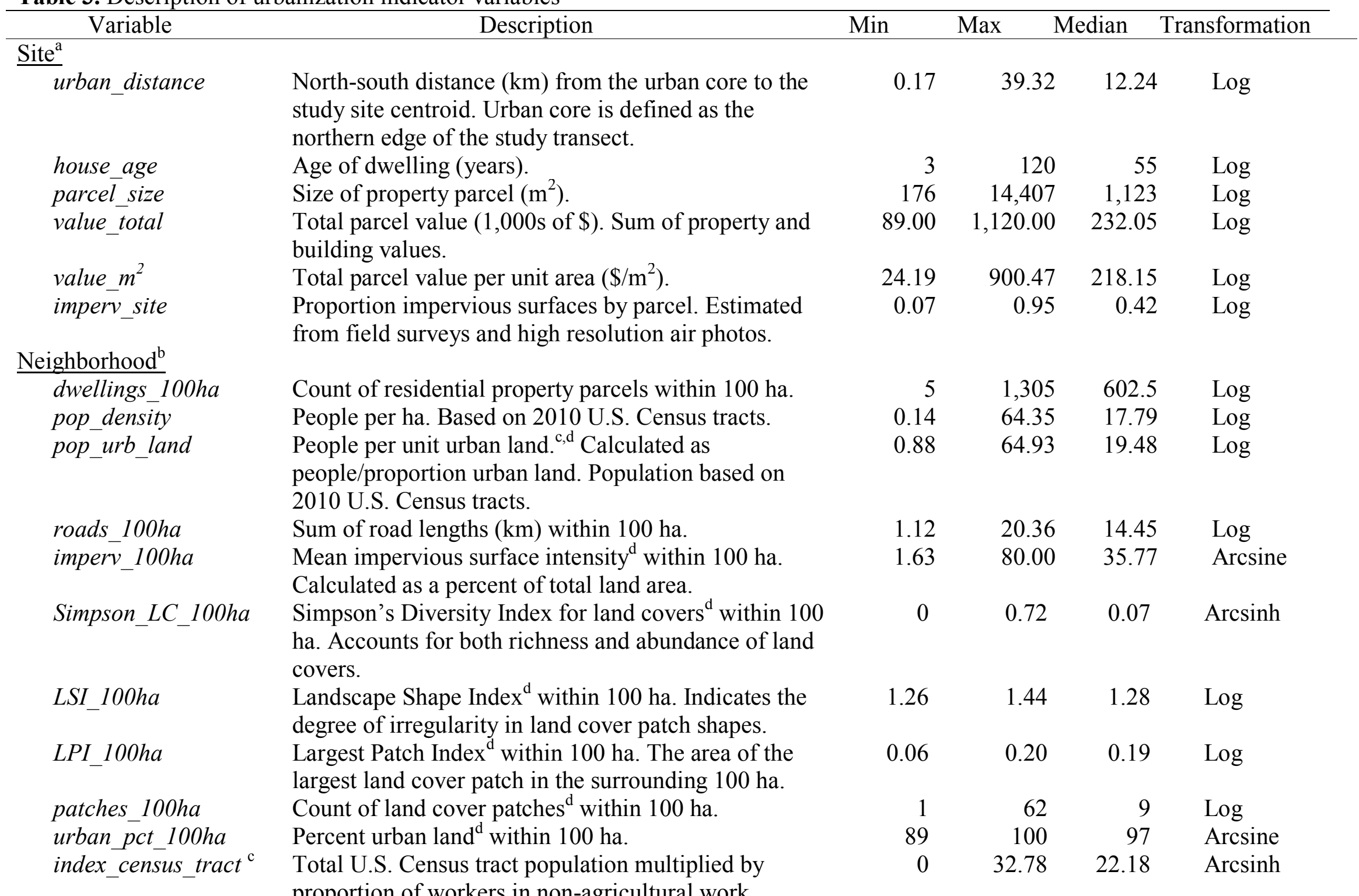


Standardized metric between 0 and 100. Based on 2010 data (U.S. Census Bureau).

index image $100 \mathrm{ha}^{\mathrm{c}}$ Index based on proportion impervious surfaces and bare soil ${ }^{\mathrm{d}}$ within 100 ha. Standardized metric between 0 and 100.

index_combined $^{\mathrm{c}}$ Average value of index_image_100ha and index census tract. Standardized metric between 0 and 100 .

${ }^{a}$ Site variables measure attributes of the individual property parcel studied.

${ }^{\mathrm{b}}$ Neighborhood variables describe characteristics of the area surrounding each study site parcel.

${ }^{c}$ For detailed index descriptions, see Weeks (2003) and Hahs and McDonnell (2006).

${ }^{\mathrm{d}}$ Based on land cover and impervious surfaces classification available from University of Minnesota Remote Sensing and Geospatial Analysis Laboratory (http://land.umn.edu). The classification used 2007 Landsat imagery at $30 \mathrm{~m}$ resolution. 
Table 4. Polynomial regression results relating urban forest structural attributes to the distancebased gradient

\begin{tabular}{lcccc}
\hline Urban forest attribute & Curve $^{\mathrm{a}}$ & Peak $^{\mathrm{b}}$ & $r^{2}$ & $p$-value \\
\hline tree_cover & -- & -- & 0.002 & 0.560 \\
tree_count & -- & -- & 0.000 & 0.990 \\
trees_ha & -- & -- & 0.008 & 0.275 \\
basal_area & cubic & mid & 0.174 & $<\mathbf{0 . 0 0 1}$ \\
DBH_median & cubic & mid & 0.124 & $<\mathbf{0 . 0 0 1}$ \\
DBH_max & cubic & mid & 0.176 & $<\mathbf{0 . 0 0 1}$ \\
tree_ht_median & -- & -- & 0.011 & 0.272 \\
tree_ht_max & cubic & mid & 0.036 & $\mathbf{0 . 0 3 9}$ \\
CB_ht_median & linear & urban & 0.068 & $\mathbf{0 . 0 0 3}$ \\
shrub_cover & linear & urban & 0.045 & $\mathbf{0 . 0 2 0}$ \\
shrub_count & linear & urban & 0.026 & $\mathbf{0 . 0 4 9}$ \\
shrubs_ha & linear & urban & 0.050 & $\mathbf{0 . 0 1 4}$ \\
street_trees & quadratic & mid & 0.374 & $<\mathbf{0 . 0 0 1}$ \\
plantable_space & -- & -- & 0.024 & 0.062 \\
\hline
\end{tabular}

${ }^{a}$ Indicates which polynomial regression best fit the data, if any.

${ }^{\mathrm{b}}$ Describes the location of the curve peak relative to urban-rural distance (urban, mid, or rural). For example, urban indicates that the attribute peaked in the urban core and decreased with distance from the urban core.

${ }^{\mathrm{c}} p$-values were adjusted for multiple testing using a false discovery rate correction. Bold values indicate $p<0.05$. 
Table 5. Varimax rotated factor analysis results for urbanization indicators

\begin{tabular}{|c|c|c|}
\hline & \multicolumn{2}{|c|}{ Factor } \\
\hline & 1 & 2 \\
\hline $\begin{array}{l}\text { Rotation sums of squared } \\
\text { loadings }\end{array}$ & 4.068 & 3.792 \\
\hline Variance explained (percent) & 33.899 & 31.598 \\
\hline Variable & \multicolumn{2}{|c|}{ Factor loadings } \\
\hline urban_distance & -0.935 & -0.159 \\
\hline house age & 0.511 & 0.442 \\
\hline parcel_size & -0.633 & -0.483 \\
\hline value_total & -0.267 & -0.443 \\
\hline imperv site & 0.537 & 0.270 \\
\hline dwellings_100ha & 0.176 & 0.935 \\
\hline pop urb land & 0.677 & 0.538 \\
\hline roads_100ha & 0.519 & 0.703 \\
\hline imperv_100ha & 0.840 & 0.348 \\
\hline patches_100ha & -0.581 & -0.458 \\
\hline urban_pct_100ha & 0.504 & 0.620 \\
\hline index_census tract & 0.340 & 0.834 \\
\hline value $m^{2}$ & \multirow{2}{*}{\multicolumn{2}{|c|}{ excluded }} \\
\hline pop density tract & \multirow{2}{*}{\multicolumn{2}{|c|}{ excluded }} \\
\hline Simpson_LC_100ha & & \\
\hline LSI $100 \bar{h} a$ & \multicolumn{2}{|c|}{$\begin{array}{l}\text { excluded } \\
\text { excluded }\end{array}$} \\
\hline LPI_looha & \multicolumn{2}{|c|}{ excluded } \\
\hline index image 100ha & \multirow{2}{*}{\multicolumn{2}{|c|}{$\begin{array}{l}\text { excluded } \\
\text { excluded }\end{array}$}} \\
\hline index combined & & \\
\hline
\end{tabular}

Excluded variables were removed due to excessive multicollinearity. Bold values indicate factor loadings $>0.71$. 
Table 6. Stepwise polynomial regression results relating urbanization gradient factors to urban forest structural attributes. Regression models were not created when urbanization factors failed to enter the stepwise model, as indicated by dashes.

\begin{tabular}{lccccc}
\hline \multicolumn{1}{c}{ Urban forest attribute } & Factor(s) $^{\mathrm{a}}$ & Curve $^{\mathrm{b}}$ & Peak $^{\mathrm{c}}$ & $r^{2}$ & $p$-value \\
\hline tree_cover & 2 & quadratic & urban & 0.052 & $\mathbf{0 . 0 4 3}$ \\
tree_count & -- & -- & -- & -- & -- \\
trees_ha & -- & -- & -- & -- & -- \\
basal_area & 1,2 & linear & urban & 0.070 & $\mathbf{0 . 0 2 3}$ \\
DBH_median & -- & - & -- & -- & -- \\
DBH_max & 1 & quadratic & mid & 0.041 & $\mathbf{0 . 0 4 9}$ \\
tree_ht_median & -- & -- & -- & -- & -- \\
tree_ht_max & 1 & quadratic & mid & 0.057 & $\mathbf{0 . 0 3 8}$ \\
CB_ht_median & 1 & linear & urban & 0.051 & $\mathbf{0 . 0 4 3}$ \\
shrub_cover & 1 & linear & urban & 0.064 & $\mathbf{0 . 0 2 5}$ \\
shrub_count & 1 & linear & urban & 0.045 & $\mathbf{0 . 0 4 7}$ \\
shrubs_ha & 1 & linear & urban & 0.069 & $\mathbf{0 . 0 2 3}$ \\
street_trees & 1 & linear & urban & 0.221 & $<\mathbf{0 . 0 0 1}$ \\
plantable_space & -- & -- & -- & -- & -- \\
\hline a Des & & - & &
\end{tabular}

${ }^{\mathrm{a}}$ Denotes which urbanization factors, if any, were used to construct the regression model ${ }^{\mathrm{b}}$ Indicates which polynomial curve best fit the data.

${ }^{\mathrm{c}}$ Describes the location of the curve peak relative to the urbanization gradient (urban, mid, or rural). For example, urban indicates a positive relationship in which the attribute was higher for characteristically urban sites and lower for characteristically rural sites.

${ }^{\mathrm{d}} p$-values were adjusted for multiple testing using a false discovery rate correction. 
Figure 1. Location of the study transect within Minnesota's Twin Cities Metropolitan Area (TCMA). On the detailed transect map, black circles denote study parcels and gray represents all residential land.

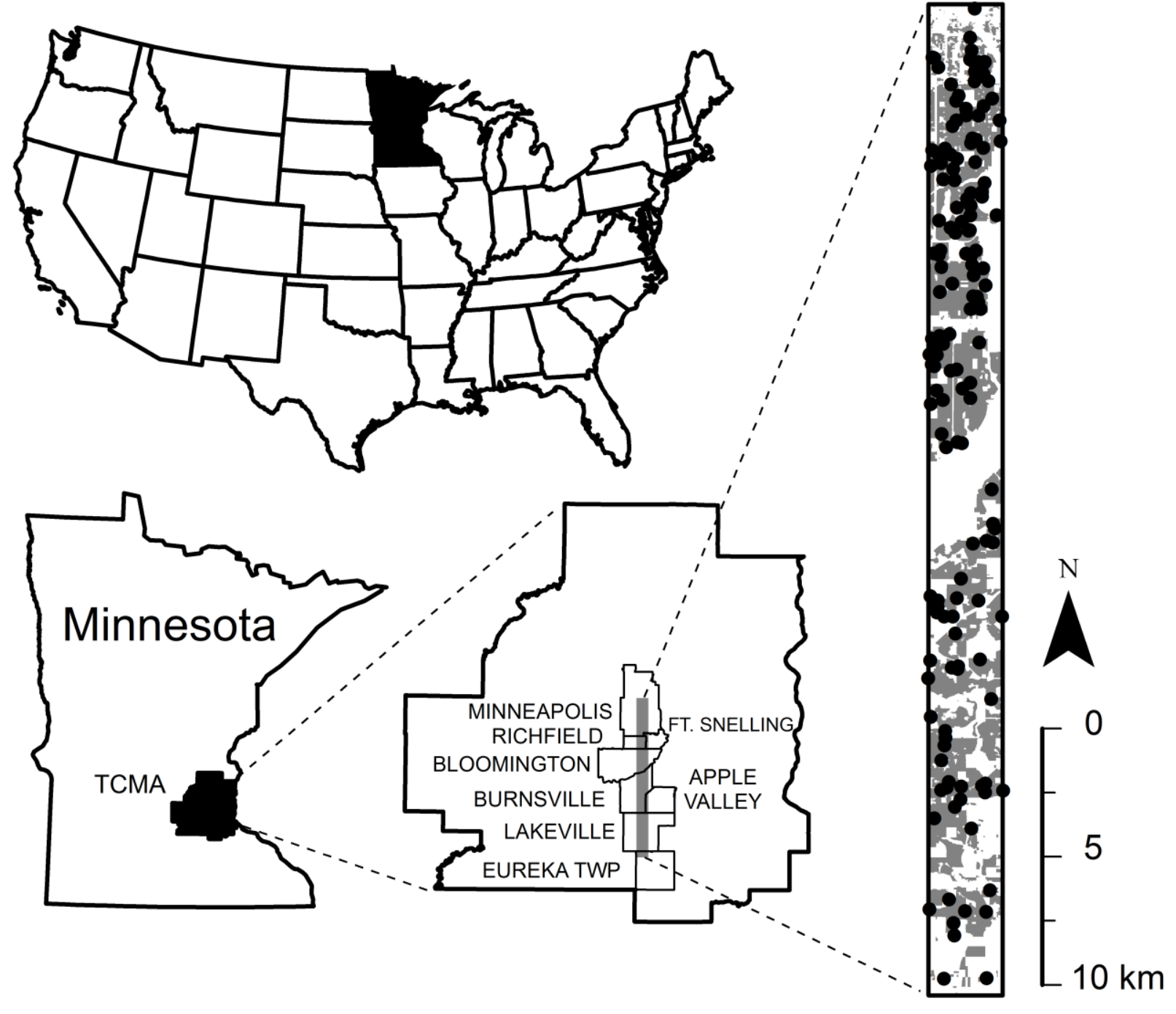


Figure 2. Pearson product-moment correlations between 100 ha study site buffers and 10, 25, and 250 ha buffers for select variables. For each buffer distance, the variables were multiplied by a factor to make them "equivalent" to 100 ha buffers (e.g., 10 ha buffer values were multiplied by $10 ; 250$ ha buffer values were multiplied by 0.4 ). Results are displayed in scatterplots to show the scaling effects of various buffer distances. Linear curves were fit for each scatterplot, and a 1-to-1 comparison line is shown for reference. All correlations are significant at $p<0.001$.
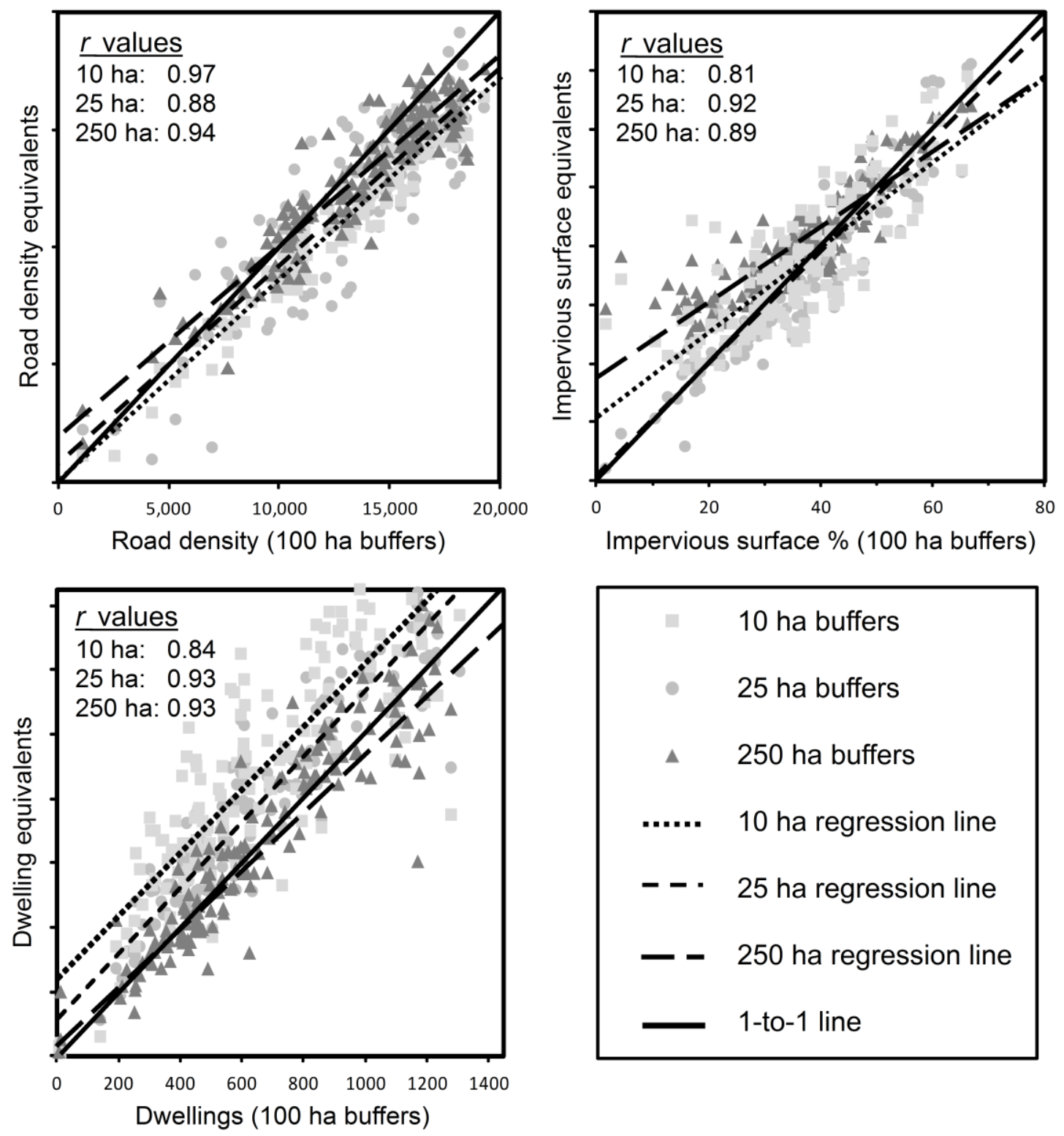
Figure 3. Urbanization factors at the 150 study parcels, categorized by quintiles from most urban (black) to least urban (white). Factors were derived from a set of nineteen urbanization indicator variables (Table 3). Factor 1 is most strongly associated with urban-rural distance and neighborhood impervious surface intensity, while factor 2 is most strongly associated with dwelling density and an index based on population and employment sector (Table 5).

\section{Factor 1 Factor 2}

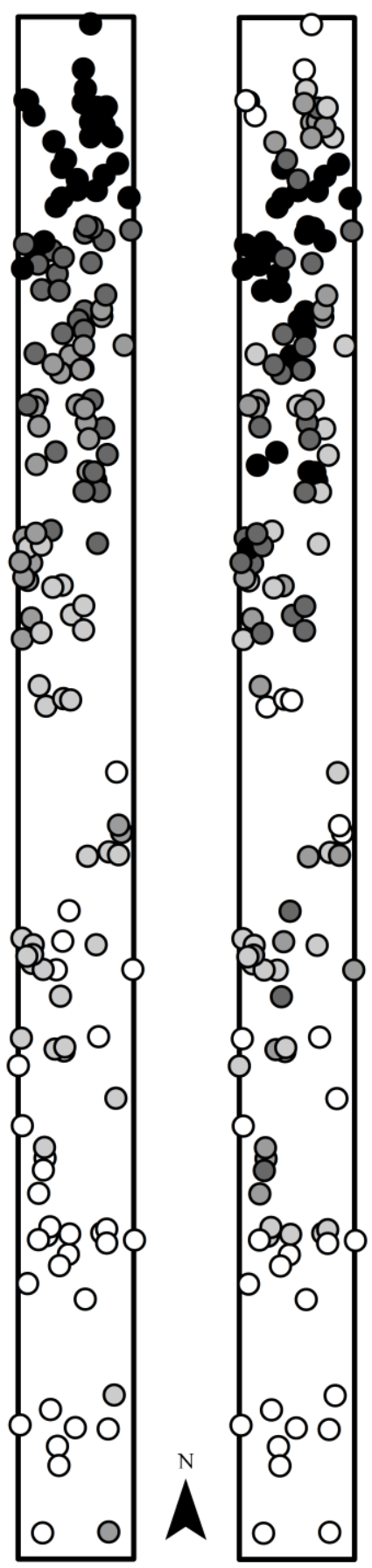

